\title{
Preoperative CYFRA 21-1 level as a prognostic indicator in resected nonsmall cell lung cancer
}

\author{
J. Niklinski*, T. Burzykowski+, W. Niklinska**, J. Laudanski*, \\ L. Chyczewski***, M. Rapellino , M. Furman*
}

\begin{abstract}
Preoperative CYFRA 21-1 level as a prognostic indicator in resected nonsmall cell lung cancer. J. Niklinski, T. Burzykowski, W. Niklinska, J. Laudanski, L. Chyczewski, M. Rapellino, M. Furman. OERS Journals Ltd 1998.

ABSTRACT: Cytokeratin 19 is particularly abundant in carcinoma of the lung. The CYFRA 21-1 assay has recently been developed for detection of a cytokeratin 19 fragment in serum. In the current study, the prognostic information provided by the CYFRA 21-1 assay in operable nonsmall cell lung cancer (NSCLC) was analysed.

Serum levels of CYFRA 21-1 were measured using an immunoradiometric assay (DiaSorin) in 94 patients with operable NSCLC. Survival and disease-free survival curves related to initial levels of this marker were estimated using the Kaplan-Meier method.

Elevated preoperative CYFRA 21-1 levels were identified in $42 \%$ of patients with NSCLC. The number of patients with elevated levels of this marker increased with tumour node metastasis (TNM) stage $(p=0.02)$. In univariate analysis elevated levels of CYFRA 21-1 were significantly associated with poor overall survival $(p<0.001)$ and with disease-free survival $(p<0.001)$. The results remained significant when the comparisons were adjusted, using the stratified log-rank test, for patient's TNM stage $(p<0.001$ for both overall and disease-free survival). Elevated preoperative levels of CYFRA 21-1 decreased the probability of survival or surviving without recurrence 15 months or more after the operation. This was confirmed by the results of the multivariate analysis.

In conclusion, CYFRA 21-1 may be an independent prognostic parameter of survival and tumour relapse in nonsmall cell lung cancer and may be useful in identifying resected cancer patients at high risk for treatment failure. Eur Respir J 1998; 12: 1424-1428.
\end{abstract}

\begin{abstract}
Depts of *Thoracic Surgery, **Histology and ***Pathology, Bialystok Medical University, Bialystok, Poland. +Biostatistical Unit, The Maria Sklodowska-Curie Memorial Cancer Center and Institute of Oncology, Warsaw, Poland. ¥Dept of Pneumonology, University of Turin, Turin, Italy.
\end{abstract}

Correspondence: J. Niklinski

Dept of Thoracic Surgery

Bialystok Medical Academy

24A M Sklodowska-Curie St

15-276 Bialystok

Poland

Fax: 48857423537

Keywords: CYFRA 21-1

lung cancer

prognosis

tumour markers

Received: November 201997

Accepted after revision July 131998

Supported by the Polish Scientific Programme (KBN 4 S403 007 07).
Lung cancer is one of the leading causes of cancer death throughout the world. Nonsmall cell lung carcinoma (NSCLC) accounts for approximately $75 \%$ of cases and represents a heterogeneous group of cancers consisting mainly of squamous cell, adenocarcinoma and large cell carcinoma [1,2]. Despite major advances in cancer treatment in the past two decades, the prognosis of patients with lung cancer has improved only minimally. The tumour node metastasis (TNM) stage is recognized as the main prognostic factor in lung cancer [3]. However, the variability in survival within staging groups required additional types of indicators, independent of stage [4].

A large number of new molecular and biological factors has been reported [5-9]. One group of molecules that has been shown promise as biomarkers is the cytokeratins. Cytokeratins and other intermediate filaments of the cell are known to be present in various normal and pathological tissues [10]. The expression of cellular cytokeratins is specific for different tissues. At present, 20 cytokeratins have been described by immunohistochemical studies. Cytokeratin 19 may be expressed in simple epithelia such as the unstratified epithelium of bronchial trees and is abundant in carcinoma of the lung [11]. Although cytokeratins are part of the cytoskeleton, some fragments might be released in the serum owing to cell lysis or tumour necrosis.

A new tumour marker assay (CYFRA 21-1), which uses two monoclonal antibodies (KS19-1 and BM19-21) against epitopes of a water-soluble fragment of cytokeratin 19 , was recently introduced $[12,13]$.

The current study examines whether elevated serum CYFRA 21-1 levels have any prognostic value in patients with resected NSCLC.

\section{Materials and methods}

The study included 94 NSCLC patients examined by the Chest Oncology Group and operated on in the Thoracic Surgery Unit at the Bialystok Medical School between January 1994 and February 1995. All of the patients underwent radical surgical resection.

Pretreatment staging procedures included physical and blood examinations, chest radiography and tomography, bronchoscopy, computed tomography (CT) of the thorax and ultrasound scanning of the liver. In addition, radioisotopic scans of bones, examination of bone marrow aspirates, and abdominal and brain CT scans were performed 
when necessary. Selected patients underwent mediastinoscopy. During operation, radical lymph node dissection was uniformly performed. Nodes were identified and submitted separately at all levels. Pathological material was reviewed specially for this study by the same pathologist. Postoperative, pathological staging (pTNM; primary tumour, regional lymph involvement, occurrence of distant metastasis) was performed by correlating the operative and histological findings [3].

At the time of analysis, 38 patients had died: 37 patients had died owing to recurrence of the disease (local recurrence or distant metastatic disease) and one patient died 34 months after surgery, owing to an unrelated cause. In this case, no tumour recurrence had been detected. In the whole group of patients the length of follow-up ranged 12-48 months. In the group of 56 surviving patients the median follow-up was 31.5 months.

To determinate CYFRA 21-1 serum levels, venous blood samples were collected from each patient before surgery, centrifuged to obtain serum samples and stored at $-80^{\circ} \mathrm{C}$ until assayed. All samples were assayed in duplicate. Serum levels of CYFRA 21-1 were measured by radioimmunoassay, using a commercial source (DiaSorin, Saluggia, Italy), following the manufacturer's instructions. The cutoff point was $3.6 \mathrm{ng} \cdot \mathrm{mL}^{-1}$.

\section{Statistical analysis}

Comparisons based on contingency tables were performed using Fisher's exact test and the exact test for trend [14]. Survival time was calculated from the date of surgery to the date of death or the last observation of a patient. Patients who were alive at the end of the follow-up were regarded as censored observations. Disease-free survival time was calculated from the date of surgery to the date of relapse or death or to the date of the last observation of a patient. Patients who were alive and disease-free at the end of the follow-up were regarded as censored observations.

Overall survival and disease-free survival curves were estimated using the Kaplan-Meier method. Ninety-five per cent confidence intervals for the estimated probability of overall and disease-free survival were calculated using asymptotic variance of the $\log -\log$ transformation of the survivor function [15].

In the univariate analysis the log-rank test and the logrank test for trend (with equally spaced coefficients [16]) were used.

In the multivariate analysis the stratified log-rank test and the proportional hazard model were used. The assumption of proportionality of hazard functions was checked graphically and using tests for time-dependent covariates [15]. Final models contained time-dependent covariates. The fit of the models was checked graphically using unstandardized integrated residuals and generalized Schoenfeld residuals [17]. Comparisons based on the models were performed using the score test [15].

All the tests performed in the univariate and multivariate analyses were two-sided. The exact tests were computed using StatXact-3 software (Cytel Software Corporation, Cambridge, MA, USA). The other methods were applied using BMDP/DYNAMIC (version 7.0, programs 1L and 2L; BMDP Statistical Software Inc., Los Angeles, CA,
USA) and STATA (version 3; Computing Resource Center, Santa Monica, CA, USA). In order to calculate the residuals to check the fit of proportional hazard models containing time-dependent covariates, a separate program was written using procedure IML of SAS (version 6.03; SAS Institute, Cary, NC, USA).

\section{Results}

At the time of diagnosis $40(42.5 \%)$ of 94 analysed patients with NSCLC had CYFRA 21-1 levels $>3.6 \mathrm{ng} \cdot \mathrm{mL}^{-1}$. The numbers of patients with an elevated CYFRA 21-1 level according to different characteristics are shown in the table 1 .

The proportion of patients with an elevated CYFRA 211 level were compared in different groups using tests for contingency tables at the $\mathrm{p}=0.01$ significance level (adjusted for multiple comparisons). The age categories (ð60, 61-63, 64-66 and >66 yrs) were formed using quartiles of the observed age distribution (to obtain four age groups of roughly equal size).

It was found that only an effect of TNM stage was marginally significant $(\mathrm{p}=0.02)$, with the proportion of patients with an elevated CYFRA 21-1 level increasing with increasing TNM stage.

\section{Overall survival}

All 94 patients with NSCLC were included in the analysis of overall survival. The length of follow-up in this group ranged 12-45 months. Thirty-eight patients died during the observation, with follow-up ranging 13-39 months (median 26.5 months). In the group of 56 surviving patients the median follow-up time was 31.5 months.

Table 1. - Proportion of patients with an elevated CYFRA 21-1 according to patients' characteristics

\begin{tabular}{|c|c|c|c|c|c|}
\hline \multirow{2}{*}{$\begin{array}{l}\text { Factor } \\
\text { Age yrs }\end{array}$} & \multicolumn{2}{|c|}{$\begin{array}{c}\text { Patients with } \\
\text { normal CYFRA } \\
21-1 \text { level } \\
n=54\end{array}$} & \multicolumn{2}{|c|}{$\begin{array}{c}\text { Patients with } \\
\text { elevated CYFRA } \\
21-1 \text { level } \\
n=40\end{array}$} & \multirow{2}{*}{$\begin{array}{l}\text { p-value } \\
0.79^{*}\end{array}$} \\
\hline & & & & & \\
\hline ð60 & 12 & (22.2) & 15 & $(37.5)$ & \\
\hline $61-63$ & 16 & (29.6) & 5 & (12.5) & \\
\hline $64-66$ & 13 & (24.1) & 8 & (20.0) & \\
\hline$>66$ & 13 & (24.1) & 12 & $(30.0)$ & \\
\hline Sex & & & & & $1.00^{\dagger}$ \\
\hline Female & 8 & (14.8) & 5 & (12.5) & \\
\hline Male & 46 & $(85.2)$ & 35 & (87.5) & \\
\hline HP & & & & & 0.19 \\
\hline $\mathrm{AC}$ & 19 & $(35.2)$ & 10 & (25.0) & \\
\hline LCC & 17 & (31.5) & 9 & (22.5) & \\
\hline $\mathrm{SqCC}$ & 18 & (33.3) & 21 & $(52.5)$ & \\
\hline TNM & & & & & $0.02 *$ \\
\hline $\mathrm{I}(\mathrm{Ia}+\mathrm{Ib})$ & 20 & (37.0) & 8 & (20.0) & \\
\hline II (IIa+IIb) & 23 & (42.6) & 15 & (37.5) & \\
\hline IIIa & 11 & (20.4) & 17 & (42.5) & \\
\hline
\end{tabular}

Data are presented as numbers with percentages in parentheses. *: Exact test for linear trend; $\div$ : Fisher's exact test; : Pearson's Chi-squared test based on exact distribution. HP: histopathological type; AC: adenocarcinoma; LCC: large cell carcinoma; SqCC: squamous cell carcinoma; TNM: tumour node metastasis stage. 
Table 2. - Results of the univariate analysis of overall and disease-free survival

\begin{tabular}{|c|c|c|c|c|}
\hline Factor & $\begin{array}{l}\text { Probability of surviving } \\
\text { Š2 yrs }(95 \% \mathrm{CI})\end{array}$ & $\mathrm{p}$-value & $\begin{array}{l}\text { Probability of surviving without } \\
\text { recurrence Š } 2 \text { yrs }(95 \% \text { CI) }\end{array}$ & $\mathrm{p}$-value \\
\hline Age yrs & & $0.19 *$ & & $0.06 *$ \\
\hline д60 & $0.741(0.532-0.867)$ & & $0.630(0.421-0.781)$ & \\
\hline $61-63$ & $0.847(0.597-0.948)$ & & $0.694(0.440-0.850)$ & \\
\hline $64-66$ & $0.835(0.570-0.944)$ & & $0.733(0.470-0.880)$ & \\
\hline$>66$ & $0.850(0.604-0.949)$ & & $0.805(0.558-0.922)$ & \\
\hline Sex & & 0.79 & & $0.66^{\dagger}$ \\
\hline Female & $0.917(0.539-0.988)$ & & $0.820(0.444-0.953)$ & \\
\hline Male & $0.801(0.692-0.875)$ & & $0.695(0.577-0.786)$ & \\
\hline $\mathrm{HP}$ & & 0.25 & & 0.29 \\
\hline $\mathrm{AC}$ & $0.763(0.544-0.887)$ & & $0.604(0.384-0.766)$ & \\
\hline $\mathrm{LCC}$ & $0.792(0.570-0.907)$ & & $0.663(0.437-0.815)$ & \\
\hline $\mathrm{SqCC}$ & $0.865(0.705-0.941)$ & & $0.809(0.641-0.904)$ & \\
\hline TNM & & $<0.001 *$ & & $<0.001 *$ \\
\hline $\mathrm{I}(\mathrm{Ia}+\mathrm{Ib})$ & $0.956(0.729-0.994)$ & & $0.873(0.656-0.957)$ & \\
\hline II (IIa+IIb) & $0.913(0.755-0.971)$ & & $0.826(0.652-0.918)$ & \\
\hline IIIa & $0.558(0.353-0.720)$ & & $0.407(0.223-0.584)$ & \\
\hline CYFRA 21-1 & & $<0.001^{+}$ & & $<0.001^{\dagger}$ \\
\hline Normal & $0.919(0.799-0.969)$ & $(<0.001)^{\ddagger}$ & $0.859(0.727-0.930)$ & $(<0.001)$ \\
\hline Elevated & $0.680(0.505-0.804)$ & & $0.513(0.340-0.661)$ & \\
\hline
\end{tabular}

*: Log-rank test for linear trend; : log-rank test; : stratified log-rank test (strata: levels of tumour node metastasis (TNM)). CI: confidence interval; HP: histopathological type; AC: adenocarcinoma; LCC: large cell carcinoma; SqCC: squamous cell carcinoma.

Five factors were investigated for their influence on survival of the patients: sex, age, TNM stage (I (Ia+Ib), II (IIa+IIb) or IIIa), histopathological type of tumour (squamous cell carcinoma (SqCC), adenocarcinoma (AC) or large cell carcinoma (LCC)) and the level of CYFRA 21-1 (normal: ð3.6, elevated: $>3.6 \mathrm{ng} \cdot \mathrm{mL}^{-1}$ ).

The univariate analysis was based on the results of the log-rank test. Taking into account the fact that multiple comparisons were made, a $\mathrm{p}=0.01$ level of significance was adopted. The results of the tests for TNM and CYFRA 211 level were found to be significant (both $\mathrm{p}<0.001$ ) (table 2).

The survival curves for the groups of patients classified according to the presence or absence of an elevated level of CYFRA 21-1 are presented in figure 1. It can be seen that the curves cross; the negative effect of an elevated level of CYFRA 21-1 manifests itself after the eighteenth month. The result of the log-rank test indicates that this effect is significant.

Since TNM stage was found to influence the survival of the patients, the group of patients with a normal level of

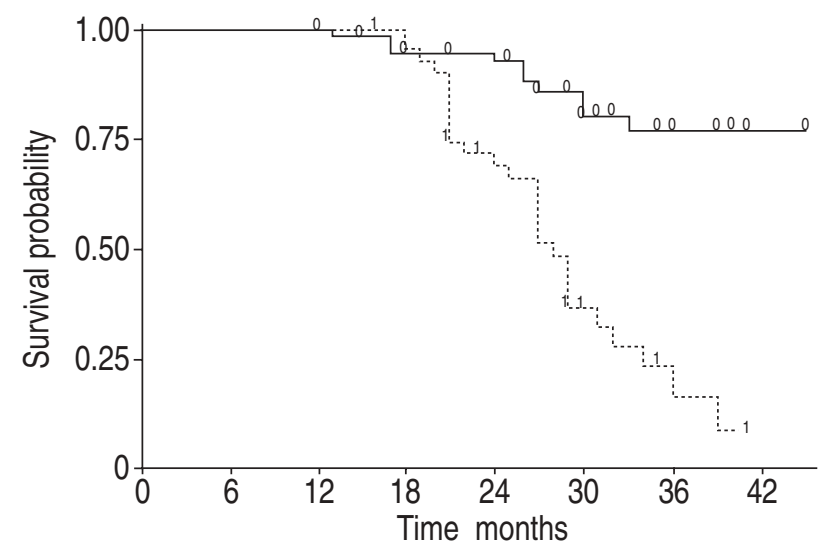

Fig. 1. - Probability of survival according to the level of CYFRA 21-1 0 and 1 indicate censored observations with 0: CYFRA 21-1 33.6 $\mathrm{ng} \cdot \mathrm{mL}^{-1} ; 1$ : CYFRA $21-1>3.6 \mathrm{ng} \cdot \mathrm{mL}^{-1}$.
CYFRA 21-1 was compared with the group with an elevated level using the stratified log-rank test. The strata were defined by TNM stage. The result of the test was significant $(\mathrm{p}<0.001)$ (table 2$)$.

To evaluate the effect of the level of CYFRA 21-1 on survival while adjusting for effects of the five remaining factors it was decided to analyse the data using Cox's proportional hazard model. However, figure 1 indicates that for CYFRA 21-1 level the assumption that hazard functions related to different levels of a factor are in the same proportion independently of time may not be true. There was no clear evidence for such an effect in the case of the remaining four factors. Thus, it was decided to use a model containing a term for interaction between time and the effect of an elevated CYFRA 21-1 level. These considerations led to the model presented in table 3 . The table contains the estimated coefficients of the model and the relative risk estimates derived from them.

The model suggests that the relative risk of death associated with an elevated CYFRA 21-1 level changes with time. According to the coefficients presented in table 3 the relative risk (RR) at time $t$ may be described by the function:

$$
\mathrm{RR}(t)=\exp (-2.94+0.20 t)=0.05(1.22)^{t}
$$

At a certain point, around 15 months after surgery, the risk of a patient with an elevated CYFRA 21-1 level becomes higher than the risk of a patient with a normal level and the difference increases with time $(p=0.001$ for the time-dependent effect of elevated CYFRA 21-1 level, table 3).

\section{Disease-free survival}

In the group of 94 analysed patients, 38 recurrences were observed. Of 38 patients who relapsed, 37 died after recurrence. Fifty-five patients were disease-free and alive 
Table 3. - Results of the multivariate analysis of overall and disease-free survival

\begin{tabular}{|c|c|c|c|c|c|c|c|c|}
\hline \multirow{2}{*}{ Covariate } & \multicolumn{4}{|c|}{ Overall survival } & \multicolumn{4}{|c|}{ Disease-free survival } \\
\hline & $\begin{array}{c}\text { Coefficient } \beta \text { of } \\
\text { the covariate } \\
\text { (SE) }\end{array}$ & & $\begin{array}{l}\text { lative risk e }{ }^{\beta} \\
(95 \% \mathrm{CI})\end{array}$ & $\mathrm{p}$-value & $\begin{array}{c}\text { Coefficient } \beta \text { of } \\
\text { the covariate } \\
\text { (SE) }\end{array}$ & & $\begin{array}{l}\text { lative risk e }{ }^{\beta} \\
(95 \% \mathrm{CI})\end{array}$ & $\mathrm{p}$-value \\
\hline Age* & $\begin{array}{ll}-0.03 & (0.03)\end{array}$ & 0.97 & $(0.92-1.03)$ & 0.29 & $\begin{array}{ll}-0.03 & (0.03)\end{array}$ & 0.97 & $(0.92-1.02)$ & 0.21 \\
\hline \multicolumn{9}{|l|}{ Sex } \\
\hline Female & 0 & & 1 & - & 0 & & 1 & - \\
\hline Male & $0.15(0.64)$ & 1.16 & $(0.33-4.08)$ & 0.81 & $0.39(0.62)$ & 1.48 & $(0.44-5.03)$ & 0.52 \\
\hline \multicolumn{9}{|l|}{$\mathrm{HP}$} \\
\hline $\mathrm{AC}$ & 0 & & 1 & - & 0 & & 1 & - \\
\hline LCC & $-0.28 \quad(0.43)$ & 0.75 & $(0.32-1.75)$ & 0.51 & $-0.29 \quad(0.43)$ & 0.75 & $(0.32-1.72)$ & 0.49 \\
\hline $\mathrm{SqCC}$ & $-1.90(0.50)$ & 0.15 & $(0.06-0.40)$ & $<0.001$ & $-1.77(0.49)$ & 0.17 & $(0.06-0.45)$ & $<0.001$ \\
\hline TNM & & & & $<0.001^{\#}$ & & & & $0.001^{\#}$ \\
\hline $\mathrm{I}(\mathrm{Ia}+\mathrm{Ib})$ & 0 & & 1 & - & 0 & & 1 & - \\
\hline II (IIa+IIb) & $0.59(0.56)$ & 1.80 & $(0.59-5.43)$ & 0.29 & $0.51(0.53)$ & 1.66 & $(0.59-4.71)$ & 0.33 \\
\hline IIIa & $2.09(0.54)$ & 8.10 & $(2.82-23.26)$ & $<0.001$ & $1.75(0.52)$ & 5.77 & $(2.09-15.96)$ & $<0.001$ \\
\hline \multicolumn{9}{|l|}{ CYFRA $21-1^{\dagger}$} \\
\hline Normal & 0 & & 1 & - & 0 & & 1 & - \\
\hline Elevated & $-2.94(1.70)$ & 0.05 & $(0.002-1.48)$ & 0.07 & $-2.77(1.60)$ & 0.06 & $(0.003-1.44)$ & 0.07 \\
\hline \multicolumn{9}{|l|}{ Elevated CYFRA 21-1 level } \\
\hline Time & $0.20(0.07)$ & 1.22 & $(1.07-1.39)$ & 0.001 & $0.21(0.07)$ & 1.24 & $(1.07-1.42)$ & 0.001 \\
\hline
\end{tabular}

*: Age scaled by median to (age-63); $\div$ : fixed effect of elevated CYFRA 21-1 level; level; time not scaled; \#: test for linear trend. CI: confidence interval; HP: histopathological type; AC: adenocarcinoma; LCC: large cell carcinoma; SqCC: squamous cell carcinoma; TNM: tumour node metastasis stage.

during the follow-up. One patient died after 34 months of observation but was lost to follow-up with regard to disease status after 31 months of observation. In the analysis the patient was treated as a censored observation at 31 months.

The same five factors as in the analysis of overall survival were investigated for an influence on the diseasefree survival of the patients. Figure 2 presents disease-free survival curves for patients with normal and elevated CYFRA 21-1 levels. The results of the univariate (table 2) and multivariate analyses (table 3 ) were similar to those obtained for overall survival. The model presented in table 3 suggests that the relative risk of recurrence or death for a pa-tient with an elevated CYFRA 21-1 level at time $t$ may be described by the function:

$$
\operatorname{RR}(t)=\exp (-2.77+0.21 t)=0.06(1.24)^{t}
$$

The function indicates that around 13 months after surgery the risk of a patient with an elevated CYFRA 21-1

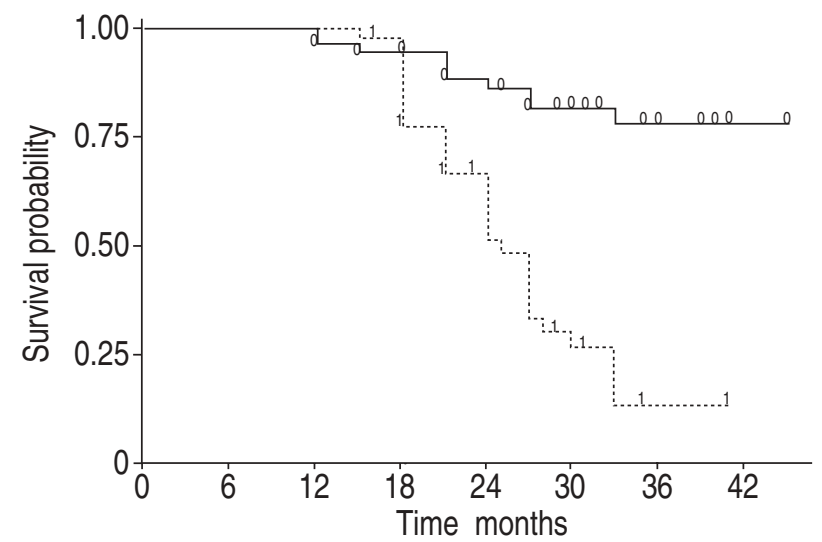

Fig. 2. - Probability of disease-free survival according to the level of CYFRA 21-1. 0 and 1 indicate censored observations. 0: CYFRA 21-1 ð3.6 ng.mL-1; 1 : CYFRA $21-1>3.6 \mathrm{ng} \cdot \mathrm{mL}^{-1}$. level becomes higher than the risk of a patient with a normal level and the difference increases with time $(\mathrm{p}=0.001$ for the time-dependent effect of elevated CYFRA 21-1 level; table 3).

\section{Discussion}

In the present study, the prognostic value of CYFRA 211 was demonstrated in NSCLC patients undergoing curative resection. Patients with elevated preoperative levels of CYFRA 21-1 had a lower probability of overall and disease-free survival of $\breve{S} 2$ yrs.

The currently used prognostic factors, such as stage of disease, performance status and histology, fail to provide an accurate prediction of the course of the disease in patients with NSCLC. The variability in survival within staging groups required additional types of indicators, independent of stage, to generate a comprehensive estimate of prognosis [4]. Recent advances in the understanding of lung cancer biology have provided insights into new, potentially significant determinants of prognosis $[5,6,8,9]$. Considerable interest has focused on a new biomarker, the soluble fragment of cytokeratin 19, CYFRA 21-1.

It has previously been reported that CYFRA $21-1$ is a sensitive marker for lung cancer, especially for squamous cell type cancer, and elevated levels of this marker were correlated with progression of tumour stage [18]. Similar observations were made by other investigators [19-23]. Following these observations the relationship between the elevated CYFRA 21-1 levels and clinical outcome of patients with resected squamous cell lung carcinoma was investigated. CYFRA 21-1 was found to be an independent prognostic factor of survival and tumour relapse [24]. In addition, the significant role of CYFRA 21-1 in the postoperative monitoring of patients with squamous cell type lung cancer for the detection of tumour recurrence has recently been reported [25]. Curative surgery resulted in a 
significant fall in preoperatively elevated CYFRA 21-1 levels to normal values, whereas steadily increasing marker levels predicted clinical relapse. Promising results have also been obtained in the comparison of the clinical value of CYFRA 21-1 assays for disease monitoring with World Health Organization response criteria with therapy assessed using standard techniques [26].

In conclusion, the results of the present study indicate that CYFRA 21-1 has a negative effect on the probability of long-term overall and disease-free survival. Thus, the preoperative CYFRA 21-1 level may be an important prognostic factor in nonsmall cell lung cancer and may be useful in identifying resected cancer patients at high risk for treatment failure.

Acknowledgement: The authors wish to thank the referees for their helpful suggestions.

\section{References}

1. Capewell S, Sudlow M. Performance and prognosis in patients with lung cancer. Thorax 1990; 45: 951-956.

2. Fry WA, Menck HR, Winchester DP. The national cancer data base report on lung cancer. Cancer 1996; 77: 19471955.

3. Mountain CF. Revision in the international system for staging lung cancer. Chest 1997; 111: 1710-1717.

4. Fielding LP, Fenoglio-Preiser CM, Freedman LS. The future of prognostic factors in outcome prediction for patients with cancer. Cancer 1992; 70: 2367-2377.

5. Richardson GE, Johnson BE. The biology of lung cancer. Semin Oncol 1993; 20: 105-127.

6. Buccheri G, Ferrigno D. Prognostic factors in lung cancer: tables and comments. Eur Respir J 1994; 7: 1350-1364.

7. Johnson BE. Molecular biology of lung cancer. In: Mendelsohn J, Howley P, Israel MA, Liotta LA, eds. The Molecular Basis of Cancer. 1st Edn. Philadelphia, WB Saunders, 1995; pp. 317-339.

8. Mountain CF. New prognostic factors in lung cancer: biologic prophets of cancer cell aggression. Chest 1995; 108: 246-254.

9. Niklinski J, Furman M. Clinical tumour markers in lung cancer. Eur J Cancer Prev 1995; 4: 129-138.

10. Moll R, Franke WW, Schiller DL, Geibzer B, Krepler R. The catalog of human cytokeratins: patterns of expression in normal epithelia, tumors and cultured cells. Cell 1982; 31: 11-24.

11. Broers JLV, Ramaekers FCS, Rot MK, et al. Cytokeratins in different types of human lung cancer as monitored by chain-specific monoclonal antibodies. Cancer Res 1988; 48: 3221-3229.
12. Pujol JL, Grenier J, Daures JP, Daver A, Pujol H, Michel FB. Serum fragment of cytokeratin subunit 19 measured by CYFRA 21-1 immunoradiometric assay as a marker of lung cancer. Cancer Res 1993; 53: 61-66.

13. Bodenmuler H, Ofenloch-Hahnle B, Lane EB, Dessauer A, Bottger V, Donie F. Lung cancer-associated keratin 19fragments: development and biochemical characterization of the new serum Enzymum Test CYFRA 21-1. Int $J$ Biol Markers 1994; 9: 75-81.

14. Agresti A. Categorical Data Analysis. 1st Edn. New York, Wiley, 1990.

15. Kalbfleish JD, Prentice RL. The Statistical Analysis of Failure Data. New York, Wiley, 1980.

16. Tarone RE, Ware J. On distribution-free tests for equality in survival distributions. Biometrica 1977; 64: 156-160.

17. Breslow WE, Prentice RL. Residuals for relative risk regression. Biometrics 1988; 75: 65-74.

18. Rapellino M, Niklinski J, Pecchio F, et al. CYFRA 21-1 as a tumour marker for bronchogenic carcinoma. Eur Respir J 1995; 8: 407-410.

19. Stieber P, Hasholzner U, Bodenmuller H, et al. CYFRA 21-1: a new marker in lung cancer. Cancer 1993; 72: 707-713.

20. Bombardieri E, Seregni E, Bogni A, et al. Evaluation of cytokeratin 19 serum fragments (CYFRA 21-1) in patients with lung cancer: results of a multicenter trial. Int $J$ Biol Markers 1994; 9: 89-95.

21. Rastel D, Ramaioli A, Cornillie F, Thirion B. CYFRA 21-1 a sensitive and specific new tumour marker for squamous cell lung cancer. Report of the first European multicentre evaluation. CYFRA 21-1 Multicentre Study Group. Eur J Cancer 1994; 30A: 601-605.

22. Ebert W, Bodenmuller H, Holzel W. CYFRA 21-1: clinical applications and analytical requirements. Scand $J$ Clin Lab Invest 1995; 55: Suppl. 221, 72-80.

23. Wieskopf B, Demangeat C, Purohit A, et al. CYFRA 21-1 as a biologic marker of non-small cell lung cancer: evaluation of sensitivity, specificity, and prognostic role. Chest 1995; 108: 163-169.

24. Niklinski J, Furman M, Burzykowski T, et al. Preoperative CYFRA 21-1 level as a prognostic indicator in resected primary squamous cell lung cancer. Br J Cancer 1996; 74: 956-960.

25. Niklinski J, Furman M, Chyczewska E, Chyczewski L, Rogowski F, Laudanski J. Diagnostic and prognostic value of the new tumour marker CYFRA 21-1 in patients with squamous cell lung cancer. Eur Respir J 1995; 8: 291-294.

26. van der Gaast A, Schoenmakers CHH, Kok TC, Blijenberg BG, Cornille F, Splinter TAW. Evaluation of a new tumour marker in patients with non-small-cell lung cancer: CYFRA 21-1. Br J Cancer 1994; 69: 525-528. 